\title{
Relationship between severity of adult community-acquired pneumonia and impairment of the antioxidant defense system
}

\author{
Rodrigo L. Castillo ${ }^{1}$, Rodrigo A. Carrasco 2,3 , Pedro I. Álvarez ${ }^{3}$, Mauricio Ruiz ${ }^{4}$, Vivian Luchsinger ${ }^{5}$, Enna Zunino ${ }^{6}$, \\ María A. Martínez ${ }^{5}$ and Luis F. Avendaño ${ }^{5}$
}

${ }^{1}$ Pathophysiology Program, Faculty of Medicine, University of Chile.

${ }^{2}$ Medicine Department, Salvador Hospital, Santiago, Chile.

${ }_{3}$ Molecular and Clinical Pharmacology Program, Institute of Biomedical Sciences, Faculty of Medicine, University of Chile.

${ }^{4}$ Medicine Department, University of Chile, Clinical Hospital.

${ }^{5}$ Virology Program, Faculty of Medicine, University of Chile.

${ }^{6}$ Infectious Disease Hospital "Dr. Lucio Córdova".

\begin{abstract}
Oxidant/antioxidant imbalance has been reported in some infectious diseases, including community-acquired pneumonia (CAP). The aim was to assess the antioxidant status in adults with CAP and its relationship with clinical severity at admission. Fifty-nine patients with CAP were enrolled and categorized at admission by the FINE score, from July 2010 to October 2012. In the same period 61 controls were enrolled. Plasma samples were obtained at admission for determination of the ferric reducing ability of plasma (FRAP) and lipid peroxidation (8-isoprostane). Erythrocyte reduced (GSH)/ oxidized (GSSG) glutathione, malondialdehyde (MDA) and antioxidant enzyme activity were assessed. Antioxidant status in adults with CAP represented by FRAP and the GSH/GSSG ratio were 16.8\% ( $\mathrm{p}=0.03$ ) and 39.7\% ( $\mathrm{p}=0.04$ ) lower than control values, respectively. In addition, FRAP values showed a positive correlation with GSH/GSSG ratio ( $r=0.852$; $p<0.02$; $\mathrm{n}=59$ ). The CAP group showed greater lipid peroxidation in both plasma and erythrocytes. The FINE score correlated negatively with FRAP $(\mathrm{r}=-0.718 ; \mathrm{p}<0.05 ; \mathrm{n}=59)$ and positively with MDA and F2 isoprostane levels $(\mathrm{r}=0.673 ; \mathrm{p}<0.05 ; \mathrm{n}=59 ; \mathrm{r}=0.892 ; \mathrm{p}<0.01 ; \mathrm{n}=59$, respectively). Antioxidant status alterations correlated with clinical severity. The FRAP assay and lipid peroxidation biomarkers may provide a useful parameter for estimating the severity and the clinical outcome of patients with CAP.
\end{abstract}

Key words: Pneumonia, oxidative stress, reduced glutathione, lipid peroxidation.

\section{INTRODUCTION}

Community-acquired pneumonia (CAP) is a frequent cause for hospital admission that results in significant costs for the health care system, and represents the most frequent cause of death of infectious origin (Butt and Swiatto, 2011). Around $10 \%$ of patients hospitalized for CAP require admission to intensive care units (ICU); lethality varies from 20 to $50 \%$ (Ewig et al., 1998). In Chile CAP is a very frequent illness, and $30 \%$ of hospitalized cases require admission to ICU, representing a relevant health burden (Arancibia and Díaz, 2005). The pathophysiology of CAP includes various mechanisms such as microorganism invasion, airway damage and activation of immune defense systems. During CAP a massive influx of activated phagocytes into the lower airways is observed, which represents the first line of defense against invading microorganisms. Polymorphonuclear neutrophils and macrophages kill these microorganisms by using reactive oxygen species (ROS) and lysosomal enzymes, including proteinases (Jones et al., 2005). This pulmonary increase in ROS concentration and proteolytic enzymes may be reflected at the systemic level as an increment in the oxidative stress and airway remodeling biomarkers in these patients (Katsoulis et al., 2005; Laskaj et al., 2007). Moreover, previous studies showed that pharmacological intervention with scavengers and antioxidants such as vitamin E could reduce proinflammatory and oxidative biomarkers in in vivo and in vitro models of CAP (Bouhafts et al., 2004; Pierrou et al., 2007; Hosakote et al., 2012).

Regardless of how oxidative stress is defined, a persistent pro-oxidant environment in the airway can modify redoxsensitive molecules and contribute to the functional impairment of the lung (Finkel, 2011). A common approach to assess oxidative stress in biological systems involves the measurement of the increase or decrease of a redox-sensitive molecule that responds to oxidative stress. In general, reliable markers of oxidative stress possess the following qualities: i) chemically unique and detectable, ii) increase or decrease during periods of oxidative stress, iii) possess relatively long half-lives, and iv) not influenced by other cellular processes (e.g., cell cycle, energy metabolism, etc.). (Halliwell et al., 2004; Valko et al., 2007). To date, most studies use exhaled markers, resulting in an invasive procedure for the patient. Therefore it is important to conduct more indirect mechanistic approaches (Lakhdar et al., 2011; Halliwell, 2012).

Moreover, the role of blood antioxidant capacity and some products of ROS damage in CAP have not been well characterized (Seet et al, 2011). After CAP diagnosis, a key element is the ability to assess the severity of the symptoms and the possible further evolution of this pathological process, to determine when the patient should be treated in each case. For this objective the use of prognostic scales is considered very valuable; these estimate the probability of 
death of a patient with CAP, leading to the decision of hospital admission, especially if complemented by individual clinical trials for each case (Blanquer et al., 2010). Indeed, for many years there has been interest in identifying early prognostic factors for CAP complications and in developing approaches able to predict prognosis and mortality (Loke et al., 2010). Some prognostic scales that provide good results in their application at admission of CAP patients are the PSI (Pneumonia Severity Index), FINE scale (Fine et al., 1997), and the CURB-65 scale (Hoare et al., 2006). However, these tools utilize only clinical aspects and routine laboratory tests, so it is necessary to find new prognostic biomarkers that could enhance the sensitivity of these prognostic tests. These scales have been widely validated in clinical trials (Capelastegui et al., 2006). However; they only show the probability of death at diagnosis and do not determine the inflammatory response of the host, which is currently considered a key aspect in the prognosis of the patient (Voiriot et al., 2011). In this view, new approaches require the evaluation of biomarkers of oxidative stress, such as antioxidant capacity and lipid peroxidation in whole blood, as an expression of a probable pro-oxidant imbalance in the host. This systemic response could be detected, in order to individualize the prognosis of CAP.

The aim of this study was to determine the association between oxidative stress biomarkers and clinical severity at admission of CAP patients.

\section{METHODS}

\subsection{Study design and subjects}

The study is a transversal clinical trial conducted to determine the relationship between clinical severity of CAP in adults and impairment of the antioxidant defense system. The study population consisted of two groups: fify-nine patients with symptoms and signs of a lower respiratory tract infection and a new infiltrate on the chest radiograph (CAP group) and a control group that included 61 patients admitted for noninfectious and non-respiratory causes. Patients were enrolled from the Emergency Services, University of Chile Clinical Hospital, from July 2010 to October 2012. Exclusion criteria included severe immunosuppression, (presence of solid organ or bone marrow transplantation, human immunodeficiency virus (HIV) infection), neutropenia $<1 \times 10^{9} / \mathrm{L}$, steroid treatment with daily doses $>20 \mathrm{mg}$ prednisolone equivalent for more than one month, co-morbidities such as congenital or previous heart surgery, advanced hepatic disease (cirrhosis), or chronic renal failure (serum creatinine $>2.0 \mathrm{mg} / \mathrm{dL}$ ). Forced vital capacity (FVC), forced expiratory volume in $1 \mathrm{~s}$ (FEV 1), the FEV 1 / FVC ratio, and forced expiratory flow values were obtained. Residual volume (RV) and total lung capacity (TLC) were measured by the helium dilution method with a Master Screen apparatus (Erich Jaeger $\mathrm{GmbH}$, Würzburg, Germany). Lung function measurements were expressed as percentages of predicted values. All subjects gave written informed consent. The local ethics committee from the University of Chile Clinical Hospital approved this protocol. This trial was conducted in accordance with the principles expressed in the Declaration of Helsinki (2000).

\subsection{Assessment of Disease Severity}

On admission day, age, smoking habits and factors predisposing to pneumonia were recorded, according to the American Thoracic Society guidelines for adult CAP. On a plain chest radiograph, unilateral/bilateral or lobar consolidation and / or pleural effusion were recorded as well. Additionally, clinical and laboratory findings were recorded to be applied in the severity prediction score (Fine et al., 1996).

\subsection{Oxidative stress related-parameters}

Four $\mathrm{ml}$ blood samples were obtained, transported cold in ice $\left(4{ }^{\circ} \mathrm{C}\right)$ and centrifuged at $3000 \times \mathrm{g}$ for $10 \mathrm{~min}$. in order to separate plasma. Erythrocyte sediment was washed three times with saline solution before being subjected to hypotonic shock to cause hemolysis. Plasma and lysed samples were stored at $-80{ }^{\circ} \mathrm{C}$ until processing for biochemical determinations. FRAP and 8-isoprostane levels were measured in plasma and malondialdehyde, antioxidant enzymes and glutathione/ glutathione disulfide ratio in erythrocytes.

Antioxidant capacity of plasma (FRAP).

This method measures the ability of the antioxidants present in plasma to reduce ferric tripyridyltriazine (Fe3+- TPTZ) to the ferrous form $(\mathrm{Fe} 2+)$, which absorbs light at $594 \mathrm{~nm}$ (Benzie and Strain, 1996). The detection limit was $10 \mu \mathrm{mol} / \mathrm{L}$, and the interassay and intra-assay coefficients of variation for FRAP were $3.0 \%$ and $1.0 \%$, respectively. The FRAP was expressed as $\mu \mathrm{mol}$ $\mathrm{Fe} 2+/ \mathrm{L}$.

\section{GSH/GSSG ratio}

Reduced glutathione (GSH) and glutathione disulfide (GSSG) levels were determined by fluorometry in erythrocytes and GSH/GSSG ratio was considered as a parameter of intracellular redox status (Hissin and Hilf, 1976). The inter- and intra-assay coefficients of variations for GSH and GSSG were $3.1 \%$ and $4.2 \%$, and $2.7 \%$ and $3.5 \%$, respectively.

8-isoprostane levels

Free F2-8-isoprostane compounds, products of non enzymatic peroxidation of arachidonic acid, were measured in plasma by enzyme immunoassay using 8-isoprostane kits (Cayman, Ann Arbor, MI) and a Sunrise micro plate reader (Tekan, Salzburg, Austria) (Collins et al., 1999). Inter- and intra-assay coefficients of variation were $5 \%$ and $7 \%$, respectively. F2-8-isoprostane levels were expressed as $\mathrm{pg} / \mathrm{mL}$.

Erythrocyte malondialdehyde

Erythrocyte lipid peroxidation was assayed by the high performance liquid chromatographic (HPLC) method to measuring the malondialdehyde-thiobarbituric acid adduct using fluorometric detection (Young and Trimble, 1991). Extraction into organic solvent or other complex sample preparation is not required. Tetramethoxypropane was used as the external standard. The intra- and inter-assay coefficients of variation were $7.3 \%$ and $8.8 \%$, respectively. The detection 
limit of the assay was $2.0 \mathrm{nM}$. Levels of lipid peroxides were expressed as $\mu \mathrm{mol} \mathrm{MDA} / \mathrm{g} \mathrm{Hb}$.

Antioxidant enzyme activity

Erythrocyte lysates were homogenized in $0.25 \mathrm{~mol} / \mathrm{L}$ sucrose for determination of $\mathrm{Cu}-\mathrm{Zn}$ superoxide dismutase $(\mathrm{Cu}-\mathrm{Zn}$ SOD) activity; or in $\mathrm{KCl}-0.010 \mathrm{~mol} / \mathrm{L}$ Tris buffer $\mathrm{pH} 7.40$ for catalase (CAT) and glutathione peroxidase (GSH-Px) activity determinations. The $\mathrm{Cu}-\mathrm{Zn}$ SOD assay is based on the SODmediated increase in the rate of autoxidation of catechols in aqueous alkaline solution to yield a chromophore with maximum absorbance at $525 \mathrm{~nm}$ (Nebot et al., 1993). One Cu-Zn SOD unit $(\mathrm{U})$ is defined as the activity that doubles the auto-oxidation background and results are expressed as U/ g hemoglobin $(\mathrm{Hb})$. CAT activity was assayed by the kinetic of breakdown of hydrogen peroxide at $240 \mathrm{~nm}$ by an aliquot of the $2400 \mathrm{x}$ $\mathrm{g}$ supernatant and expressed as the first order reaction rate constant (k) / g Hb (Aebi, 1974). Soluble GSH-Px activity was measured in the cytosolic fraction $(100,000 \times \mathrm{g}$ supernatant) by the reduction of glutathione disulfide coupled to NADPH oxidation by glutathione reductase, spectrophotometrically (Flohé and Gunzler, 1984). One GSH-Px unit is defined as the activity that oxidizes $1 \mu \mathrm{mol}$ of NADPH per minute expressed as $\mathrm{U} / \mathrm{g} \mathrm{Hb}$. All reagents were purchased from Sigma-Aldrich (St. Louis, MO, USA), Merck (Darmstadt) and Riedel-de Häen (Germany), and were of the highest commercial grade available.

\subsection{Statistical analysis}

Results were expressed as means \pm standard deviation (SD) for continuous variables. The Shapiro-Wilk test and distribution plots were used to test normality of distribution. Normally distributed variables were compared by t-tests. Non-normally distributed variables were expressed by median and interquartile ranges and compared with the two-sample Wilcoxon rank-sum test. Correlation between functional and biochemical parameters were analyzed by either Pearson or Spearman tests, according to the distribution of variables. Differences were considered statistically significant at $\mathrm{P}<0.05$. Statistical analysis was performed using STATA version 10.00 .

\section{RESULTS}

\subsection{Oxidative stress and antioxidant-related parameters.}

Eligible patients with CAP $(n=59)$ and control patients $(n=61)$ were enrolled. The two groups showed similar baseline demographics, pulmonary functional parameters and clinical laboratory tests (Table 1 ). White blood cell count was $49.6 \%$ higher in patients with CAP at admission $(p<0.05)$. These parameters indicate that the clinical characteristics of the groups were similar, differing only in the inflammatory state present in patients with CAP.

Plasma and erythrocyte oxidative stress and antioxidantrelated parameters in CAP and control patients are shown in Table 2. Antioxidant status in adults with CAP represented by FRAP and the GSH/GSSG ratio were $16.8 \%(\mathrm{p}=0.03)$ and $39.7 \%$ $(\mathrm{p}=0.04)$ lower than control values, respectively. In addition, FRAP values showed a positive correlation with the GSH/ GSSG ratio ( $\mathrm{r}=0.852 ; \mathrm{p}<0.02 ; \mathrm{n}=59$ ) (Fig. 1). Statistically nonsignificant differences between CAP and control patients were found in antioxidant enzyme activities. These parameters reflect the correlation between extra-and intracellular redox markers.

Lipid peroxidation

F2 isoprostane plasma, an in vivo lipid peroxidation parameter which reflects the systemic damage from free radicals in

\section{TABLE 1}

Demographic and clinical characteristics of patients

\begin{tabular}{|c|c|c|}
\hline & $\begin{array}{c}\text { Control } \\
\text { group } \\
(\mathrm{n}=61)\end{array}$ & $\begin{array}{l}\text { CAP } \\
\text { group } \\
(\mathrm{n}=59)\end{array}$ \\
\hline \multicolumn{3}{|l|}{ Demographics } \\
\hline Age (yrs) & $67 \pm 2$ & $65 \pm 3$ \\
\hline Sex, (Male/female) & $65 / 14$ & $63 / 18$ \\
\hline Smoking history, (pack-yr) & $45 \pm 6$ & $48 \pm 9$ \\
\hline BMI $(\mathrm{Kg} / \mathrm{m} 2)$ & $31.6 \pm 3.0$ & $30.7 \pm 2.2$ \\
\hline \multicolumn{3}{|l|}{ Comorbidities } \\
\hline Systemic hypertension, n (\%) & $27(34.1)$ & $29(35.8)$ \\
\hline Diabetes mellitus, n (\%) & $39(49.3)$ & $42(51.8)$ \\
\hline Hypercholesterolemia, n (\%) & $36(45.5)$ & $38(46.9)$ \\
\hline COPDt, n (\%) & $12(15.1)$ & $18(22.2)$ \\
\hline Asthma, n (\%) & $9(11.3)$ & $11(13.5)$ \\
\hline \multicolumn{3}{|l|}{ Pharmacological treatments } \\
\hline Aspirin, $\mathrm{n}(\%)$ & $48(60.7)$ & $49(60.4)$ \\
\hline Statins, n $(\%)$ & $31(39.2)$ & $32(39.5)$ \\
\hline ACE $\neq$ inhibitors, $\mathrm{n}(\%)$ & $41(51.8)$ & $49(60.4)$ \\
\hline ARBs§, n $(\%)$ & $18(22.7)$ & $19(23.4)$ \\
\hline$\beta$-blockers, n (\%) & $45(56.9)$ & $48(58.1)$ \\
\hline Insulin, $\mathrm{n}(\%)$ & $7(8.8)$ & $8(9.8)$ \\
\hline Sulfanilylurea, n (\%) & $8(10.1)$ & $11(13.5)$ \\
\hline Biguanides, n (\%) & $19(24.0)$ & $21(25.9)$ \\
\hline Inhaled $\beta$-agonists, n (\%) & $17(21.5)$ & $16(19.7)$ \\
\hline Inhaled corticosteroids, $\mathrm{n}(\%)$ & $10(12.6)$ & $13(16.0)$ \\
\hline \multicolumn{3}{|l|}{ Laboratory test } \\
\hline FEV1, \% predicted & $101.3 \pm 3$ & $95.6 \pm 2$ \\
\hline FEV1/FVC ratio, $\%$ & $78.7 \pm 2$ & $79.3 \pm 1$ \\
\hline $\mathrm{PaO} 2, \mathrm{~mm} \mathrm{Hg}$ & $88.4 \pm 2$ & $85.6 \pm 2$ \\
\hline $\mathrm{PaCO} 2, \mathrm{~mm} \mathrm{Hg}$ & $38.7 \pm 3$ & $41.9 \pm 1$ \\
\hline WCC, x109/L & $6,31 \pm 0,52$ & $9,43 \pm 1,02^{*}$ \\
\hline
\end{tabular}

Values are mean \pm SD or median (interquartile range). The categorical variables are expressed in frequency (\%). Significant differences: ${ }^{*} \mathrm{p}<0.05$ vs Control (Student's t-test)

COPD ${ }^{\dagger}$, Chronic obstructive pulmonary disease; $\mathrm{ACE}^{\ddagger}$, Angiotensin I converting enzyme; $\mathrm{ARBs}^{\S}$, Angiotensin II receptor blockers; FEV , forced expiratory volume in 1s; FEV 1, FVC ratio, Tiffeneau index; $\mathrm{PaO}_{2}$, arterial oxygen pressure; $\mathrm{PaCO}_{2}$, arterial carbon dioxide pressure; WCC, white cell count. 
this pro-oxidant state, showed $33.3 \%$ higher level in CAP patients than in control patients. Also, plasma and erythrocyte malondialdehyde levels were $32.4 \%$ and $30.2 \%$ higher with respect to levels in patients who did not develop CAP, respectively $(\mathrm{p}<0.05)$. These data are presented in Table 2 .

TABLE 2

Oxidative stress and antioxidant related-parameters

\begin{tabular}{|c|c|c|}
\hline & $\begin{array}{l}\text { Control } \\
\text { group } \\
(n=61)\end{array}$ & $\begin{array}{l}\text { CAP } \\
\text { group } \\
(n=59)\end{array}$ \\
\hline \multicolumn{3}{|l|}{ Parameters } \\
\hline $\mathrm{FRAP}^{*}(\mu$ moles $/ \mathrm{L})$ & $328.5 \pm 12.1$ & $273.3 \pm 9.7^{*}$ \\
\hline GSH $/ \mathrm{GSSG}^{+}$ratio & $5.54 \pm 0.17$ & $3.34 \pm 0.11^{*}$ \\
\hline $\begin{array}{l}\text { Erythrocyte malondialdehyde } \\
\text { ( } \mu \text { moles/g Hb) }\end{array}$ & $0.76 \pm 0.06$ & $0.99 \pm 0.08^{* *}$ \\
\hline $\begin{array}{l}\text { Plasma malondialdehyde } \\
(\mu \text { moles/L) }\end{array}$ & $0.71 \pm 0.08$ & $0.94 \pm 0.07^{*}$ \\
\hline $\begin{array}{l}\text { F2-isoprostane levels } \\
\text { (pg/dL) }\end{array}$ & $26.14 \pm 1.8$ & $45.2 \pm 1.8^{*}$ \\
\hline $\begin{array}{l}\text { Catalase activity } \\
(\mathrm{k} / \mathrm{g} \mathrm{Hb}) \neq\end{array}$ & $271.3 \pm 6.8$ & $265.7 \pm 5.9$ \\
\hline $\begin{array}{l}\text { Superoxide dismutase activity } \\
(\mathrm{U} / \mathrm{g} \mathrm{Hb})\end{array}$ & $1395.45 \pm 121$ & $1528.33 \pm 118$ \\
\hline $\begin{array}{l}\text { Glutathione peroxidase activity } \\
(\mathrm{U} / \mathrm{g} \mathrm{Hb})\end{array}$ & $5.74 \pm 10.21$ & $5.91 \pm 10.15$ \\
\hline
\end{tabular}

Values are mean \pm SD. Significant differences: ${ }^{*} p<0.05 ;{ }^{* *} p<0.01$ vs Control (Student's t-test)

FRAP*, ferric reducing ability of plasma; $k$; ${ }^{\dagger} \mathrm{GSH}$, reduced glutathione; GSSG, disulfide glutathione; $¥ \mathrm{~K}$, first order kinetic constant of breakdown of hydrogen peroxide.

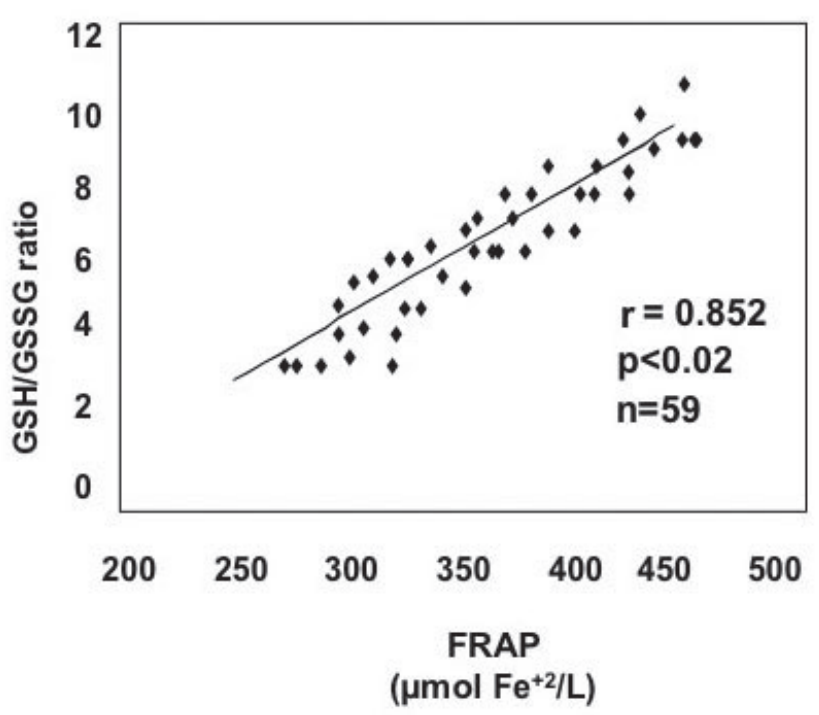

Figure 1. The relationship between FRAP and GSH/GSSG ratio. The correlation was established through Pearson's test $(r=0.852$; $\mathrm{p}<0.01 ; \mathrm{n}=59$ ). Results are means of duplicate patient samples.
3.2 Relationship between oxidative stress and clinical parameters.

The FINE score correlated negatively with FRAP ( $\mathrm{r}=-0.718$; $\mathrm{p}<0.05 ; \mathrm{n}=59$ ) (Fig. 2A) and positively with MDA level ( $\mathrm{r}=0.673$; $\mathrm{p}<0.05 ; \mathrm{n}=59)$ (Figure 2B) and $\mathrm{F} 2$ - isoprostane level $(\mathrm{r}=0.892$; $\mathrm{p}<0.01 ; \mathrm{n}=59$ ) (Figure 2C).

\section{DISCUSSION}

In CAP, similarly to other causes of infectious disease, an early identification of the patients with higher risk is very relevant. A reliable method of assessing the severity of pneumonia may potentially improve the triage or initial management of patients by helping clinicians to determine whether close monitoring and aggressive treatment is more appropriate than conservative management. However, accurately assessing the severity of pneumonia can be challenging, so a number of scales based on prognostic factors have been designed to identify patients at high risk of death, as well as those at low risk who may require less vigilance (Menéndez et al., 2009). These scales could enhance the sensitivity and the prognosis if associated with current biomarkers, in this case oxidative stress-related parameters, which would add the risk factor given by redox imbalance that would be associated with highest severity. An impairment of the antioxidant defense system in CAP patients is demonstrated by lower FRAP values and higher values of lipid peroxidation plasma and erythrocytes (Table 1) with respect to control patients. These findings are in agreement with previous studies (Bouhafs et al., 2004; Pierrou et al., 2007; Hosakote et al., 2012). Another factor to consider in the analysis is prior pharmacological treatment. Various trials have described some antioxidant and pro-oxidant effects associated with the consumption of medications (Pignatelli et al., 2012; Dinicolantonio et al., 2013). However, no significant differences were found between groups (Table 1). This also shows an efficient randomization process. In addition, an enhancement in superoxide production and a lower total antioxidant capacity have been also reported in this condition, explained partly by a decrease in platelet superoxide dismutase activity (Laskaj et al., 2009). The magnitude of the decrease in the values of antioxidant capacity in this study were similar to those described in the trials of Cemek et al., 2006 (23\%) and Laskaj et al., 2009 (17.2\%) with a smaller number patients $(n=30)$. The control values of this parameter are in accordance with FRAP in patients without CAP. Others studies have also demonstrated an increase of lipid peroxidation products in whole blood of these patients. Accordingly, increased serum MDA levels in acute pulmonary infection have been reported in both children (Cemek et al., 2006), and in adult patients (Kinnula et al., 2008).

The molecular mechanism of damage in CAP included various mediators. First, phagocyte response, an essential component of the defense system, results in increased ROS production. The effects of these substances in the airway as well as in other organs depend on ROS concentration and time of exposure. In general, higher levels of ROS produce damage in biomolecules (e.g. lipid peroxidation) and induce intracellular signaling pathways leading to cell death, mainly through apoptosis (Valko et al., 2007). Second, CAP association with an impairment of the antioxidant capacity could also contribute to the enhancement of cell damage (Table 2 and Fig. 2A) Thus it was reported that glutathione depletion in 


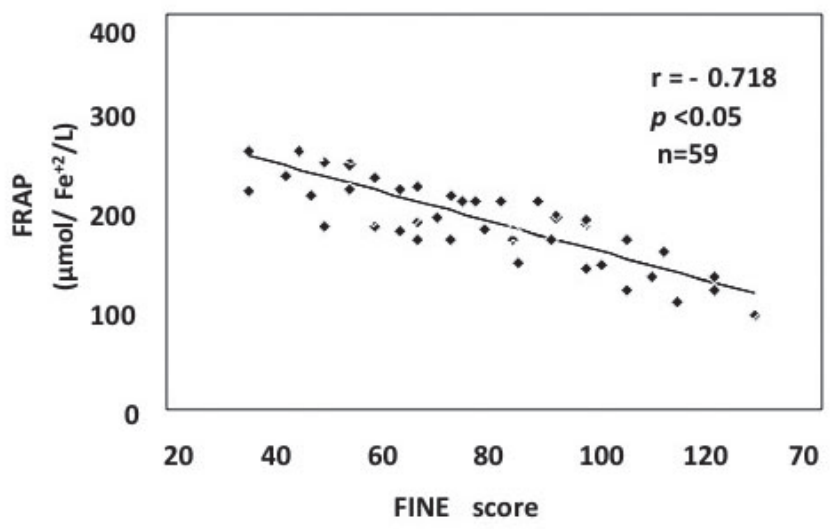

Figure 2A. The relationship between FRAP and FINE score. The correlation was established through Pearson's test $(r=-0.718 ; p<$ $0.05 ; n=59$ ). Results are means of duplicate patient samples.

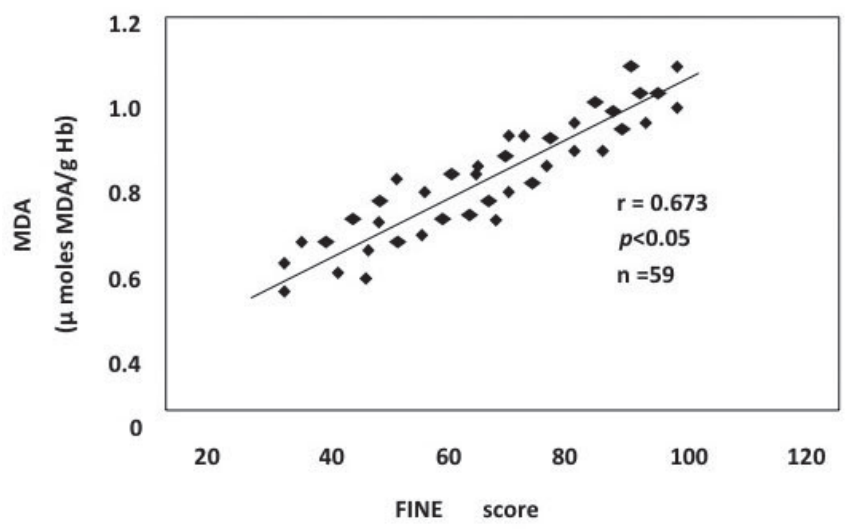

Figure 2B. The relationship between MDA levels and FINE score. The correlation was established through Pearson's test $(r=0.673$; $\mathrm{p}<0.05 ; n=59$ ). Results are means of duplicate patient samples.

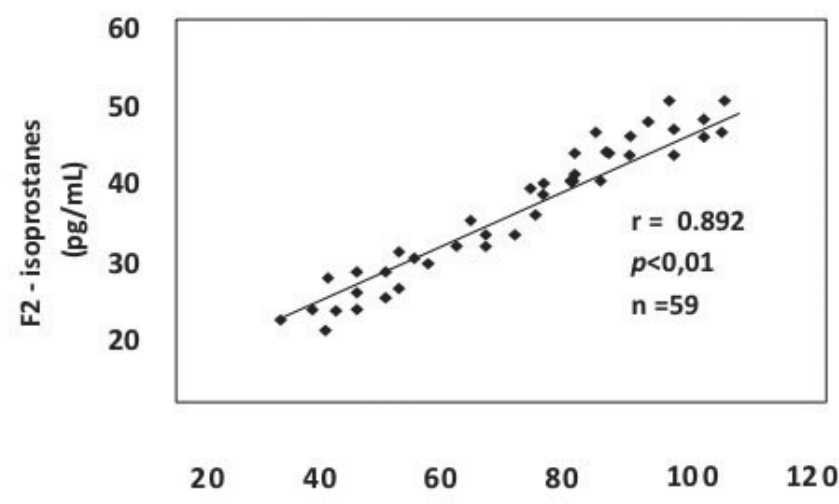

FINE score

Figure 2C. The relationship between 8-isoprostane levels and FINE score. The correlation was established through Pearson's test $(r$ $=0.892 ; \mathrm{p}<0.01 ; \mathrm{n}=59$ ). Results are means of duplicate patient samples. lung epithelial cells is associated with initiation of apoptosis, as assessed by ceramide accumulation (Tasaka et al., 2008). In contrast, defense mechanisms could be activated by moderately increased ROS through survival pathways, as demonstrated in vitro (Jia et al., 2008) and in an in vivo model of lung injury (e.g. anti-inflammatory effects) (Xiao et al., 2012). Cytoprotection is partly mediated by the nuclear factor (erythroid 2-related factor Nrf2) that controls the antioxidant response element (ARE)-dependent gene regulation in response to oxidative stress. Upon activation, Nrf2 mediates the induction of a spectrum of cytoprotective proteins including antioxidant enzymes, protection against epithelial damage in oxidative stress settings such as asthma, chronic obstructive pulmonary disease and CAP. Temporal analysis of pulmonary global gene expression after LPS challenge revealed higher expression of large numbers of proinflammatory genes associated with the innate immune response at as early as 30 minutes in lungs of Nrf2-deficient mice, indicating severe immune dysregulation (Thimmulappa et al., 2006). In CAP, the magnitude of infectious and inflammatory processes (ROS burst) in airways as a consequence of the acute microbial invasion is not adequately counteracted by the antioxidant defense system response. However, an association has not been found between this pro-oxidant status and clinical severity of CAP. For this reason it is very important to determine antioxidant status in CAP patients, in order to estimate the magnitude of the organism response to the infection at admission. Moreover, the antioxidant response observed in several studies depended on the cell type in which it was determined. For example, some studies showed a genomic response through ROS-nrf2 pathways in cells with nuclei such as lung tissue, a factor that produces a difference with our study (Gao et al., 2008; Edeas et al., 2009). In our study, we use erythrocyte lysate, wherein the activity may reflect transient changes that may not be statistically significant.

Regarding oxidative stress biomarkers, 8-isoprostane has been validated to explore the occurrence of oxidative stress in various lung diseases such as sarcoidosis, streptococcal pneumonia, chronic obstructive pulmonary disease and asthma. Previously, 8-isoprostane has been implicated in the pathophysiology of asthma according to the pattern, clinical severity and type disease. In agreement with these studies, our data show that both plasma F2 isoprostane and malondialdehyde levels in CAP patients presented a positive correlation with CAP severity (FINE score) (Fig. 2B and 2C). On the other hand, the FINE score correlated negatively with plasma antioxidant capacity (FRAP) at admission (Fig. 2A). Recently, an elevated lipid peroxidation in the erythrocytes in the acute phase of CAP has been reported, as well as a decrease in both the content of reduced glutathione and superoxide dismutase and catalase activities (Ageeva et al., 2007). However, other studies have been performed mainly in bronchoalveolar lavage fluid, a more invasive procedure than that used in this study. In addition, the serial measurement of local 8-isoprostane concentration does not provide a suitable estimation of the antioxidant defense system for determining the clinical course of CAP.

The glutathione system plays a key role in the control of pro-inflammatory processes in the lungs, being involved in immune modulation, remodeling of the extracellular matrix, apoptosis and mitochondrial respiration (Yang et al., 2006). In CAP, the role of glutathione in the pathogenesis 
of microorganism invasion or antioxidant non-enzymatic response has not been characterized. Cemek et al. (2006), studied antioxidant status in children with acute pneumonia, finding that all antioxidant compounds were decreased, i.e. vitamin C, vitamin E and GSH levels, compared to the control group. However, few clinical trials support the relationship between GSH levels and CAP severity (Berger et al., 2006; Lai et al., 2010). The protective mechanism is based on the redox environment in lung fluids, and is one of the important factors in determining the contribution of innate and adaptive immune systems against infection, independent of etiology. In the normal lung an extremely high level of extracellular antioxidant concentration is able maintain this compartment in a highly reduced state to facilitate the maintenance of an efficient immune response (Crapo, 2003). Accordingly, the negative correlation between FINE and FRAP (Figure 2A) may indicate that the lower antioxidant concentration in the whole blood of CAP patients at admission is able to facilitate the invasion of microorganisms and the eventual production of clinical complications.

In conclusion, our results indicate the occurrence of an oxidative imbalance in CAP patients. The finding that the FINE score was negatively correlated with the FRAP level and positively with MDA level suggests a relevant role of oxidative stress in the severity of this infectious process. Indeed, these data suggest that treatment with antioxidants should be considered as a supplementary therapy in patients with CAP at admission. The use of antioxidant supplementation is associated with pharmacological doses administered at a defined clinical moment In contrast with the other pleiotropic effects prescribed as usual pharmacotherapy for these patients. Finally, it seems that measurement of plasma oxidative stress biomarkers may be useful as an additional severity criterion of pneumonia, although its clinical significance needs to be explored further.

\section{ACKNOWLEDGEMENTS}

The authors thank Mr. Diego Soto for technical support in the oxidative stress assays.

This work was supported by the national FONDECYT grant (initiation) 11110426.

\section{REFERENCES}

AEBI H (1974) Catalase. Methods in Enzymatic Analysis: Academic Press. New York. pp 673-678.

AGEEVA TS, ZHAVORONOK TV, TETENEVA FF, KRIVONOGOV NG, RIAZANTSEVA NV, ZAVADOVSKAIA VD, STEPOVAIA EA, DUBODELOVA AV, PETINA GV, STARIKOV IUV, DANILENKO VIU (2007) Extrahospital pneumonias: the clinico-scintigraphic characterization and oxidative balance of cells. Klin Med (Mosk) 85:43-48.

ARANCIBIA HF, DÍAZ PO (2005) Severe community-acquired pneumonia in adults. Rev Chil Infectol 22:s46-s51.

BENZIE IF, STRAIN JJ (1996) The ferric reducing ability of plasma (FRAP) as a measure of "antioxidant power": the FRAP assay. Anal Biochem 239:70-76.

BERGER MM, EGGIMANN P, HEYLAND DK, CHIOLÉRO RL, REVELLY JP, DAY A, RAFFOUL W, SHENKIN A (2006) Reduction of nosocomial pneumonia after major burns by trace element supplementation: aggregation of two randomised trials. Crit Care 10:R153.

BLANQUER J, SANZ F (2010) Community-acquired pneumonia. Arch Bronconeumol 46:26-30.

BOUHAFS RK, JARSTRAND C, ROBERTSON B (2004) Lipid peroxidation of lung surfactant in experimental neonatal group B streptococcal pneumonia. Lung 182:61-72.
BUTT S, SWIATLO E (2011) Treatment of community-acquired pneumonia in an ambulatory setting. Am J Med 124:297-300.

CAPELASTEGUI A, ESPANA PP, QUINTANA JM, AREITIO I, GORORDO I, EGURROLA M, BILBAO A (2006) Validation of a predictive rule for the management of community-acquired pneumonia. Eur Respir 27:151-157.

CEMEK M, CAKSEN H, BAYIROĞLU F, CEMEK F, DEDE S (2006) Oxidative stress and enzymic-non-enzymic antioxidant responses in children with acute pneumonia. Cell Biochem Funct 24:269-273.

COLLINS CE, QUAGGIOTTO P, WOOD L, O'LOUGHLIN EV, HENRY RL, GARG ML (1999) Elevated plasma levels of F2 alpha isoprostane in cystic fibrosis. Lipids 34:551-556.

CRAPO JD (2003) Oxidative stress as an initiator of cytokine release and cell damage. Eur Respir J 44:4s-6s.

DINICOLANTONIO JJ, LAVIE CJ, FARES H, MENEZES AR, O'KEEFE JH (2013) Meta-analysis of carvedilol versus beta 1 selective beta-blockers (atenolol, bisoprolol, metoprolol, and nebivolol). Am J Cardiol 111: 765769.

EDEAS M. (2009) Antioxidants, controversies and perspectives : How can the future of clinical studies using Antioxidants be explained? J Soc Biol 203:271-280.

EWIG S, RUIZ M, MENSA J, MARCOS MA, MARTINEZ JA, ARANCIBIA F, NIEDERMAN MS, TORRES A (1998) Severe community-acquired pneumonia. Assessment of severity criteria. Am J Respir Crit Care Med 158:1102-1108.

FINE MJ, AUBLE TE, YEALY DM, HANUSA BH, WEISSFELD LA, SINGER DE, COLEY CM, MARRIE TJ, KAPOOR WN (1997) A prediction rule to identify low-risk patients with community-acquired pneumonia. N Engl J Med 336:243-250.

FINE MJ, SMITH MA, CARSON CA, MUTHA SS, SANKEY SS, WEISSFELD LA (1996) Prognosis and outcomes of patients with community-acquired pneumonia. A meta-analysis. JAMA 275:134-141.

FINKEL T (2011) Signal transduction by reactive oxygen species. J Cell Biol 194:7-15.

FLOHÉ L, GUNZLER W A (1984) Assays of glutathione peroxidase: Methods in Enzymology. Colowic SP and Kaplan NO. New York. pp:114-121.

GAO F, KINNULA VL, MYLLÄRNIEMI M, OURY TD (2008) Extracellular superoxide dismutase in pulmonary fibrosis. Antioxid Redox Signal 10:343-354.

HALLIWELL B, WHITEMAN M (2004) Measuring reactive species and oxidative damage in vivo and in cell culture: how should you do it and what do the results mean? Br J Pharmacol 142:231-255.

HALLIWELL B (2012) Free radicals and antioxidants: updating a personal view. Nutr Rev 70:257-265.

HISSIN PJ, HILF R (1976) A fluorometric method for determination of oxidized and reduced glutathione in tissues. Anal Biochem 74:214-226.

HOARE Z, LIM WS (2006) Pneumonia: update on diagnosis and management. BMJ 332:1077-1079.

HOSAKOTE YM, KOMARAVELLI N, MAUTEMPS N, LIU T, GAROFALO RP, CASOLA A (2012) Antioxidant mimetics modulate oxidative stress and cellular signaling in airway epithelial cells infected with respiratory syncytial virus. J Physiol Lung Cell Mol Physiol 303:L991-L1000.

JIA L, XU M, ZHEN W, SHEN X, ZHU Y, WANG W (2008) Novel antioxidative role of calreticulin in protecting A549 human type II alveolar epithelial cells against hypoxic injury Am J Physiol Cell Physiol 294:C47-C55.

JONES MR, SIMMS BT, LUPA MM, KOGAN MS, MIZGERD JP (2005) Lung NFkappaB activation and neutrophil recruitment require IL-1 and TNF receptor signaling during pneumococcal pneumonia. J Immunol 175:75307535.

KATSOULIS K, KONTAKIOTIS T, BALTOPOULOS G, KOTSOVILI A, LEGAKIS IN (2005) Total antioxidant status and severity of communityacquired pneumonia: are they correlated?. Respiration 72:381387.

KINNULA VL, MYLLÄRNIEMI M (2008) Oxidant-antioxidant imbalance as a potential contributor to the progression of human pulmonary fibrosis. Antioxid Redox Signal 10:727738.

LAI KY, NG WY, OSBURGA CHAN PK, WONG KF, CHENG F (2010) Highdose N-acetylcysteine therapy for novel H1N1 influenza pneumonia. Ann Intern Med 152:687688.

LAKHDAR R, DENDEN S, KASSAB A, LEBAN N, KNANI J, LEFRANC G, MILED A, CHIBANI JB, KHELIL AH (2011) Update in chronic obstructive pulmonary disease: role of antioxidant and metabolizing gene polymorphisms. Exp Lung Res 37:36475.

LASKAJ R, DODIG S, CEPELAK I, KUZMAN I (2007) Gammaglutamyltransferase activity and total antioxidant status in serum and platelets of patients with communityacquired pneumonia. Arch Med Res 38:424431. 
LASKAJ R, DODIG S, CEPELAK I, KUZMAN I (2009) Superoxide dismutase, copper and zinc concentrations in platelet-rich plasma of pneumonia patients. Ann Clin Biochem 46:123-128.

LOKE YK, KWOK CS, NIRUBAN A, MYINIT PK (2010) Value of severity scales in predicting mortality from community-acquired pneumonia: systematic review and metaanalysis. Thorax 65:884-890.

MENÉNDEZ R, MARTÍNEZ R, REYES S, MENSA J, FILELLA X, MARCOS MA, MARTÍNEZ A, ESQUINAS C, RAMIREZ P, TORRES A (2009) Biomarkers improve mortality prediction by prognostic scales in community-acquired pneumonia. Thorax 64:587-591.

NEBOT C, MOUTET M, HUET P, XU JZ, YADAN JC, CHAUDIERE J (1993) Spectrophotometric assay of superoxide dismutase activity based on the activated autoxidation of a tetracyclic catechol. Anal Biochem 214:442451.

PIERROU S, BROBERG P, O'DONNELL RA, PAWŁOWSKI K, VIRTALA R, LINDQVIST E. (2007) Expression of genes involved in oxidative stress responses in airway epithelial cells of smokers with chronic obstructive pulmonary disease. Am J Respir Crit Care Med 175:577-586.

PIGNATELLI P, CARNEVALE R, PASTORI D, CANGEMI R, NAPOLEONE L, BARTIMOCCIA S, NOCELLA C, BASILI S, VIOLI F (2012) Immediate antioxidant and antiplatelet effect of atorvastatin via inhibition of Nox2. Circulation 126:92-103.

SEET RC, LEE CY, LOKE WM, HUANG SH, HUANG H, LOOI WF, CHEW ES, QUEK AM, LIM EC, HALLIWELL B (2011) Biomarkers of oxidative damage in cigarette smokers: which biomarkers might reflect acute versus chronic oxidative stress? Free Radic Biol Med 50:1787-1793.

TASAKA S, AMAYA F, HASHIMOTO S, ISHIZAKA A (2008) Roles of oxidants and redox signaling in the pathogenesis of acute respiratory distress syndrome. Antioxid Redox Signal 10:739-753.

THIMMULAPPA RK, LEE H, RANGASAMY T, REDDY SP, YAMAMOTO M, KENSLER TW, BISWAL S (2006) Nrf2 is a critical regulator of the innate immune response and survival during experimental sepsis. J Clin Invest 116:984-995.

VALKO M, LEIBFRITZ D, MONCOL J, CRONIN MT, MAZUR M, TELSER J. (2007) Free radicals and antioxidants in normal physiological functions and human disease. Int J Biochem Cell Biol 39:44-84.

VOIRIOT G, DURY S, PARROT A, MAYAUD C, FARTOUKH M (2011) Nonsteroidal antiinflammatory drugs may affect the presentation and course of community-acquired pneumonia. Chest 139:387-394.

XIAO X, YANG M, SUN D, SUN S (2012) Curcumin protects against sepsisinduced acute lung injury in rats. J Surg Res 176:e31-e39.

YANG P, EBBERT JO, SUN Z, WEINSHILBOUM RM (2006) Role of the glutathione metabolic pathway in lung cancer treatment and prognosis: a review. J Clin Oncol 24:1761-1769.

YOUNG IS, TRIMBLE ER (1991) Measurement of malondialdehyde in plasma by high performance liquid chromatography with fluorimetric detection. Ann Clin Biochem 28:504-508. 
